\title{
TLC-densitometric analysis of $\alpha$-escin in bulk drug substance and in pharmaceutical dosage forms
}

\author{
Malgorzata Dolowy ${ }^{\star 1}$, Alina Pyka-PajaK ${ }^{1}$, Katarzyna Filip ${ }^{2}$, Joanna Zagrodzka ${ }^{2}$ \\ ${ }^{1}$ Department of Analytical Chemistry, Faculty of Pharmacy, Medical University of Silesia in Katowice, 4 Jagiellonska, 41-200 \\ Sosnowiec, Poland \\ ${ }^{2}$ R\&D Analytical Chemistry Department, Pharmaceutical Research Institute, 8 Rydygiera, 01-793 Warsaw, Poland
}

\begin{tabular}{|c|c|}
\hline ARTICLE INFO & ABSTRACT \\
\hline $\begin{array}{l}\text { Received } 08 \text { January } 2015 \\
\text { Accepted } 16 \text { September } 2015\end{array}$ & $\begin{array}{l}\text { A quite simple and rapid TLC-densitometric method for the identification of a-escin } \\
\text { (Aescin) in bulk drug substances was developed. In so doing, different chromatographic }\end{array}$ \\
\hline $\begin{array}{l}\text { Keywords: } \\
\alpha \text {-escin, } \\
\text { TLC, } \\
\text { densitometry, } \\
\text { triterpene compounds. }\end{array}$ & $\begin{array}{l}\text { conditions, including various mobile and stationary phases, were tested. A TLC- } \\
\text { densitometric determination of the examined compound was performed without using } \\
\text { visualizing reagent, yet with the use of appropriate dipping reagents, in order to obtain } \\
\text { reliable UV-densitometric measurements of a-escin - a substance which has weak } \\
\text { chromophore groups. Herein, the application of a mobile phase containing n-butanol- } \\
\text { acetic acid-water in volume composition } 30: 7: 13 \text {, the use of silica gel } 60 \mathrm{~F}_{254} \text { plates with } \\
\text { concentrating zone, and subsequent application of } 10 \% \text { sulphuric acid in ethanol or } 5 \% \\
\text { vanillin in methanol/sulphuric acid, respectively, provided the best results in a TLC- } \\
\text { densitometric study of } \alpha \text {-escin. The described method was successfully employed to } \\
\text { identify a-escin in commercial samples that were in an oral dosage form (tablets) and } \\
\text { also in the form of gel containing } 20 \mathrm{mg} \text { of } \alpha \text {-escin. }\end{array}$ \\
\hline
\end{tabular}

\section{INTRODUCTION}

Escin (Aescin) is a natural mixture of triterpene saponins isolated from the seeds of the horse chestnut (Aesculus hipocastanum). The saponins present in escin belong to two series of isomers, $\alpha$-escin and $\beta$-escin [3]. However, data drawn from current literature demonstrate that isomer a shows lower pharmacological activity than $\beta[10]$. Therefore, only few reports indicate the pharmacological activity of the isomeric form $\alpha$, e.g., its improvement in osteopenia in rats [10]. A number of research studies have revealed that $\beta$-escin exhibits remarkable anti-inflammatory, anti-edematous and also vasoprotective properties [7,10-12]. Thus, it is widely used in the treatment of chronic venous insufficiency, hemorrhoids, inflammation and cerebral edema. In current medical practice, $\beta$-escin is commonly employed to inhibit proliferation and to induce the apoptosis of various types of cancer cells and endothelial cells. The anti-cancer effect of $\beta$-escin against colon, hepatocellular and leukemia cells has been reported in vivo and in vitro by many medical researchers $[9,16]$. It should be noted that $\beta$-escin appears

\footnotetext{
* Corresponding author

e-mail: mdolowy@sum.edu.pl
}

to be the main active component of escin mixtures present in major available pharmaceutical products. Commercial preparations popular in Poland contain both isomeric forms of this compound.

Many analytical methods have been developed for the direct determination of the escin complex or its isomers $\alpha$ and $\beta$, respectively. Among these are spectrophotometry, radioimmunoassay and chromatography $[1,6,12-13]$. In regard to the identification of escin in pharmaceutical formulations, radioimmunoassay, spectrophotometric analysis or TLC techniques are conventionally utilized. What is more, in recent years, HPLC-MS/MS, has been employed, being a rapid and sensitive method, to quantify escin in biosamples e.g., in rat and human plasma, urine, feces and bile, after oral administration of escin during preclinical pharmacokinetic studies of the drug $[8,14,15]$.

According to the European Pharmacopeia, thin-layer chromatography is generally recommended for quality control assessment of escin (as mixture of similar triterpenoids saponins obtained from the seeds of Aeculus hippocastanum) in pure powder and in pharmaceutical dosage form [5]. For the purpose of the quantitative determination of this compound, the UV-spectrophotometric method is 
mentioned in this Pharmacopeia. Only few papers report on the TLC-densitometric analysis of complex escin ( $\alpha$ and $\beta$ ) in pharmaceutical formulations, especially in oral dosage forms $[2,4]$. Therefore, the aim of this work was the development of a TLC-densitometric method in all its aspects: selection of the most suitable stationary and mobile phase, and formulating a suitable mixture of various organic solvents, for the determination of $\alpha$-escin as a pure powder. In addition to this, the effective utilization of different visualizing reagents in TLC-densitometric analysis of $\alpha$-escin was assessed. Moreover, the limit of detection (LOD) and also the limit of quantification (LOQ) of $\alpha$-escin as detected under optimum chromatographic conditions, were determined. The chromatographic conditions described in this paper were successfully used for the identification of $\alpha$-escin in both the simple and in the complex pharmaceutical formulations which are commercially available in the forms of tablets and gel, respectively.

\section{MATERIALS AND METHODS}

\section{Chemicals and Samples}

Aescin ( $\alpha$-escin, $\geq 95 \%$ ), pure powder was purchased from Sigma-Aldrich (St. Louis, MO, USA). Pharmaceutical formulations containing $20 \mathrm{mg}$ of Aescin in form of tablets and gel (TEVA PHARMACEUTICALS, Poland) were used as samples. The following components of mobile phases: chloroform, acetone, acetonitrile, n-hexane, ethyl acetate, acetic acid (99\%), methanol, n-butanol, isopropanol and formic acid were purchased from POCh (Gliwice, Poland). All solvents were analytical grade. Sulphuric acid 95\%, phosphomolybdic acid, cobalt (II) chloride, vanillin, iodide, iodide potassium and also anisaldehyde from $\mathrm{POCh}$, (Gliwice, Poland) were applied so as to prepare the respective dipping reagents needed to visualize the spots.

\section{Apparatus}

- densitometer: TLC Scanner 3 Camag (Muttenz, Switzerland) operated in absorbance and equipped with WinCATS 1.4.2 software, the source of the radiation were deuterium and tungsten lamps,

- chromatographic chamber for $20 \mathrm{~cm} \times 10 \mathrm{~cm}$ plates (Art. 0.222.5221, Camag, Muttenz, Switzerland),

- Camag micropippettes sized $5 \mathrm{~mL}$ (Muttenz, Switzerland) were used to apply the solutions to the plates,

- chromatographic plates $10 \mathrm{~cm} \times 10 \mathrm{~cm}$ cut from $20 \mathrm{~cm}$ $\times 20 \mathrm{~cm}$ (E. Merck, Germany) for NP-TLC analysis: aluminium plates precoated with silica gel $60 \mathrm{~F}_{254}$ (Art. 1.05554), aluminium plates precoated with silica gel 60 (Art. 1.05553), aluminium plates precoated with silica gel $60 \mathrm{~F}_{254}$ with concentrating zone (Art. 1.05583), and aluminium plates precoated with silica gel 60 and kieselguhr $\mathrm{F}_{254}$

\section{Preparation of the Standard Solution}

A standard solution of the examined $\alpha$-escin was prepared through the dissolution of $40 \mathrm{mg}$ of this substance in $10 \mathrm{~mL}$ of methanol, so as to obtain a concentration of $4 \mathrm{mg} / \mathrm{mL}$. Further dilution of this solution by the use of methanol allows the production of standard solutions at concentrations in the range of $0.01-1 \mathrm{mg} / \mathrm{mL}$. These were then applied for the determination of the LOD and LOQ values of $\alpha$-escin by means of the developed TLC-densitometric method.

\section{Preparation of the Sample Solutions}

A quantity of the powdered tablets or the gel corresponding to $40 \mathrm{mg}$ of $\alpha$-escin was suspended separately in $10 \mathrm{~mL}$ of methanol and next agitated for 15 minutes. Both suspensions were filtered through a membrane filter of $0.45 \mathrm{~mm}$. The filtrates containing $4 \mathrm{mg} / \mathrm{mL}$ of $\alpha$-escin were directly deposited on the chromatographic plates, together with the standard solution, for qualitative analysis.

\section{Preparation of Visualizing Reagents}

The solutions of the following visualizing reagents: $10 \%$ sulphuric acid in ethanol; $5 \%$ vanillin in methanol/sulphuric acid; $10 \%$ phosphomolybdic acid in ethanol; $2 \%$ anisaldehyde in methanol/sulphuric acid; $2 \%$ iodine/potassium iodide; $2 \%$ cobalt (II) chloride in methanol were prepared according to the procedures set out in the literature [13].

\section{NP-TLC Qualitative Analysis of $\alpha$-escin in Bulk Drug Substance and in Pharmaceutical Preparations}

In order to find suitable chromatographic conditions for the TLC-densitometric analysis of $\alpha$-escin, such as appropriate mobile phase, stationary phase, and also appropriate visualizing reagent (so as to obtain a stable coloration of the $\alpha$-escin spots), the amount of $5 \mu \mathrm{L}$ of standard solution at concentration of $4 \mathrm{mg} / \mathrm{mL}$ of this compound was spotted onto various chromatographic plates. These were of $10 \mathrm{~cm}$ $\times 10 \mathrm{~cm}$ in size (E. Merck, Art. 1.05554, Art. 1.05553, Art. 1.05567 , Art. 1.05583), and were activated at a temperature of $120^{\circ} \mathrm{C}, 30$ minutes before use. The plates were then developed by means of applying $50 \mathrm{~mL}$ of the mobile phase to a distance of approximately $8 \mathrm{~cm}$ from baseline, in a TLC chamber, for the $20 \mathrm{~cm} \times 10 \mathrm{~cm}$ plates. The following mobile phases were investigated: methanol-water $(40: 10$, $35: 15,30: 20,10: 40, \mathrm{v} / \mathrm{v})$; acetone-n-hexane $(8.5: 41.5$, $35: 15, \mathrm{v} / \mathrm{v})$, acetone-water $(30: 15, \mathrm{v} / \mathrm{v})$, methanol-ethyl acetate-water (30:7:13, v/v/v), acetonitrile-water (40:10, $\mathrm{v} / \mathrm{v}$ ), chloroform-methanol (47:3), isopropanol-water-formic acid $(35: 12: 3, \mathrm{v} / \mathrm{v} / \mathrm{v})$, acetonitrile-acetic acid-water (30:7:13, $\mathrm{v} / \mathrm{v} / \mathrm{v})$, acetonitrile-isopropanol-acetic acid $(15: 15: 7, \mathrm{v} / \mathrm{v} / \mathrm{v})$, n-butanol-acetic acid-water $(30: 7: 13,30: 5: 15, \mathrm{v} / \mathrm{v} / \mathrm{v})$ and n-hexane-ethyl acetate-acetic acid $(25: 20: 5, \mathrm{v} / \mathrm{v} / \mathrm{v})$. After developing, the plates were dried at room temperature $\left(20 \pm 2^{\circ} \mathrm{C}\right)$, in a fume cupboard, for $24 \mathrm{~h}$. Next, the chromatograms were visualized by dipping the plates in the solution of the respective visualizing reagent or were densitometrically scanned without the use of a visualizing reagent. The densitomeric scanning of the obtained chromatograms was performed after heating the plates at a temperature of $110^{\circ} \mathrm{C}$ for 15 minutes, immediately after the visualization of the spots by the applied reagents came about. The exception to the procedure was for those which had been visualized by way of application of a $2 \%$ iodine/potassium iodide solution. The stability of the color of spots of $\alpha$-escin which have been produced using the various visualizing reagents was confirmed by comparing the peak area of the detected compound measured densitometrically in an appropriate time interval 
after the visualization came about, e.g., immediately following the visualization of the spots, after 15 minutes, 30 minutes, 1 h, 2 h, 3 h, 4 h and also after 5 hours.

\section{Densitometric and Spectrodensitometric Measurements in the Qualitative Analysis of $\alpha$-escin in Bulk Drug Sub- stance and in Pharmaceutical Formulations}

Herein, spectrodensitometric scanning was done using a Camag TLC Scanner 3 (Muttenz, Switzerland), which was controlled by WinCATS 1.4.2 software. All spectrodensitometric measurements were conducted in the reflectance absorbance mode, at the respective (optimal) wavelength in each case. Deuterium and tungsten lamps served as sources of radiation. The scanning speed was $20 \mathrm{~mm} / \mathrm{s}$, and the data resolution was $100 \mu \mathrm{m} / \mathrm{step}$. The slit dimension was kept at $10.0 \mathrm{~mm} \times 0.40 \mathrm{~mm}$. Densitograms and also spectrodensitograms of $\alpha$-escin from pure powder and also from the pharmaceutical formulations obtained by way of various chromatographic systems were used to describe the optimal conditions for the qualitative and also the quantitative analysis of the examined compound. Each analysis was repeated three times.

\section{Detection Limit and Quantification Limit (LOD and LOQ) of $\alpha$-escin Determined by TLC-Densitometry}

In order to estimate with good accuracy, both parameters: the LOD value - the lowest amount of $\alpha$-escin that can be detected in a bulk substance by applied TLC-densitometry, and also LOQ - the lowest amount of $\alpha$-escin that can be quantitatively determined by the use of TLC-densitometry (under applied chromatographic conditions), two wellknown equations based on S (slope of the calibration curve) and $\sigma$ (standard deviation of the response) of specific calibration curve prepared for standard solutions of the analyte were used.

\section{RESULTS}

The main purpose of this work was to ascertain suitable chromatographic conditions for both the simple and rapid TLC-densitometric analysis of $\alpha$-escin content in bulk drug substances. These procedures may then be applied in future quality control assessment of this substance when generating various pharmaceutical formulations. Table 1 summarizes the results of a set of TLC-densitometric measurements of $\alpha$-escin $\left(R_{F}\right.$ and $\left.\lambda_{\text {max }}\right)$ which has been gathered through examining all applied chromatographic plates developed using n-butanol-acetic acid-water in a volume composition of $30: 7: 13$.

The data seen in Table 2 is of the values of limit of detection (LOD) and also the quantification (LOQ) in $\mu \mathrm{g} / \mathrm{spot}$ of examined $\alpha$-escin (Aescin) in pure powder as investigated using NP-TLC, combined with densitometry, under optimal chromatographic conditions. This data set includes the use of the two chosen as the best of all applied visualizing reagents: sulphuric acid and vanillin. In order to estimate the influence of both visualizing reagents on the LODs and LOQs of $\alpha$-escin, the results of these parameters were compared with those which have been determined without the employment of a visualizing agent.

Figure 1 and 2 are of the densitograms (Figure $1 \mathrm{~A}$ and Figure $2 \mathrm{~A}$ ) and spectrodensitograms (Figure $1 \mathrm{~B}$ and Figure 2 B) which have been obtained for the studied $\alpha$-escin (Aescin), coming from standard solutions of pure substance (ES), tablets (ET) and gel (EG), respectively, by way of using the described optimal chromatographic conditions: n-butanol-acetic acid-water (30:7:13, v/v/v), and chromatographic plates for NP-TLC precoated with silica gel $60 \mathrm{~F}_{254}$. These were visualized by way of employing one of two effective dipping reagents: $10 \%$ sulphuric acid in ethanol or $5 \%$ vanillin in methanol/sulphuric acid.

Table 1. Parameters of TLC-densitometric identification of a-escin using n-butanol-acetic acid-water in volume composition 30:7:13 and by different dipping reagents

\begin{tabular}{|c|c|c|c|c|c|c|c|c|}
\hline \multirow[b]{3}{*}{ Chromatographic plates } & \multirow[b]{3}{*}{$\mathrm{R}_{\mathrm{F}}$} & \multicolumn{7}{|c|}{ Wavelength of maximum absorption $\lambda_{\max }[\mathrm{nm}]$} \\
\hline & & \multicolumn{7}{|c|}{ Dipping reagent } \\
\hline & & $\begin{array}{l}\text { without } \\
\text { dipping } \\
\text { reagent }\end{array}$ & $\begin{array}{l}10 \% \text { sulphuric } \\
\text { acid in ethanol }\end{array}$ & $\begin{array}{c}5 \% \text { vanillin } \\
\text { in methanol/ } \\
\text { sulphuric acid }\end{array}$ & $\begin{array}{c}10 \% \\
\text { phosphomolybdic } \\
\text { acid in ethanol }\end{array}$ & \begin{tabular}{|c|}
$2 \%$ \\
anisaldehyde \\
in methanol/ \\
sulphuric acid \\
\end{tabular} & $\begin{array}{l}2 \% \text { iodine/ } \\
\text { potassium } \\
\text { iodide }\end{array}$ & $\begin{array}{c}2 \% \text { cobalt (II) } \\
\text { chloride in } \\
\text { methanol }\end{array}$ \\
\hline $\begin{array}{l}\text { Silica gel } 60 \mathrm{~F}_{254} \\
\text { Art. } 1.05554 \\
\end{array}$ & $0.44 \pm 0.01$ & 221 & 277 & 650 & 700 & 290 & 221 & 224 \\
\hline $\begin{array}{l}\text { Silica gel } 60 \mathrm{~F}_{254} \text { with } \\
\text { concentrating zone } \\
\text { Art. } 1.05583\end{array}$ & $0.51 \pm 0.01$ & 221 & 277 & 650 & 700 & 290 & 221 & 224 \\
\hline $\begin{array}{l}\text { Silica gel } 60 \\
\text { Art. } 1.05553 \\
\end{array}$ & $0.45 \pm 0.02$ & 221 & 277 & 650 & 700 & 290 & 221 & 224 \\
\hline $\begin{array}{c}\text { Silica gel } 60 \text { and kieselguhr } \mathrm{F}_{254} \\
\text { Art. } 1.05567\end{array}$ & $0.50 \pm 0.01$ & 221 & 277 & 650 & 700 & 290 & 221 & 224 \\
\hline
\end{tabular}

Table 2. The limit of detection (LOD) and quantification (LOQ) of $\alpha$-escin examined in bulk drug substances using NP-TLC combined with densitometry, under different chromatographic conditions

\begin{tabular}{|c|c|c|c|c|c|c|}
\hline \multirow{3}{*}{ Chromatographic plates } & \multicolumn{6}{|c|}{ Visualization system applied in TLC-densitometric analysis of a-escin } \\
\hline & \multicolumn{2}{|c|}{ Without visualizing reagent } & \multicolumn{2}{|c|}{$\begin{array}{l}\text { Using } 5 \% \text { vanillin in methanol/ } \\
\text { sulphuric acid }\end{array}$} & \multicolumn{2}{|c|}{ Using $10 \%$ sulphuric acid in ethanol } \\
\hline & $\begin{array}{c}\text { LOD } \\
{[\mu \mathrm{g} / \mathrm{spot}]}\end{array}$ & $\begin{array}{c}\text { LOQ } \\
{[\mu \mathrm{g} / \mathrm{spot}]}\end{array}$ & $\begin{array}{c}\text { LOD } \\
{[\mu \mathrm{g} / \mathrm{spot}]}\end{array}$ & $\begin{array}{c}\text { LOQ } \\
{[\mu \mathrm{g} / \mathrm{spot}]}\end{array}$ & $\begin{array}{c}\text { LOD } \\
{[\mu \mathrm{g} / \mathrm{spot}]}\end{array}$ & $\begin{array}{c}\text { LOQ } \\
{[\mu \mathrm{g} / \mathrm{spot}]}\end{array}$ \\
\hline $\begin{array}{l}\text { Silica gel } 60 \mathrm{~F}_{254} \\
\text { Art. } 1.05554\end{array}$ & 2.470 & 7.484 & 0.654 & 1.984 & 0.634 & 1.920 \\
\hline $\begin{array}{l}\text { Silica gel } 60 \\
\text { Art. } 1.05553\end{array}$ & 11.390 & 34.515 & 0.454 & 1.375 & 0.172 & 0.522 \\
\hline $\begin{array}{l}\text { Silica gel } 60 \mathrm{~F}_{254} \text { with concentrating zone } \\
\text { Art. } 1.05583\end{array}$ & 0.586 & 1.776 & 0.330 & 0.999 & 0.395 & 1.196 \\
\hline $\begin{array}{l}\text { Silica gel and kieselguhr } 60 \mathrm{~F}_{254} \\
\text { Art. } 1.05567\end{array}$ & 2.267 & 6.870 & 0.918 & 2.783 & 0.243 & 0.738 \\
\hline
\end{tabular}


(A)

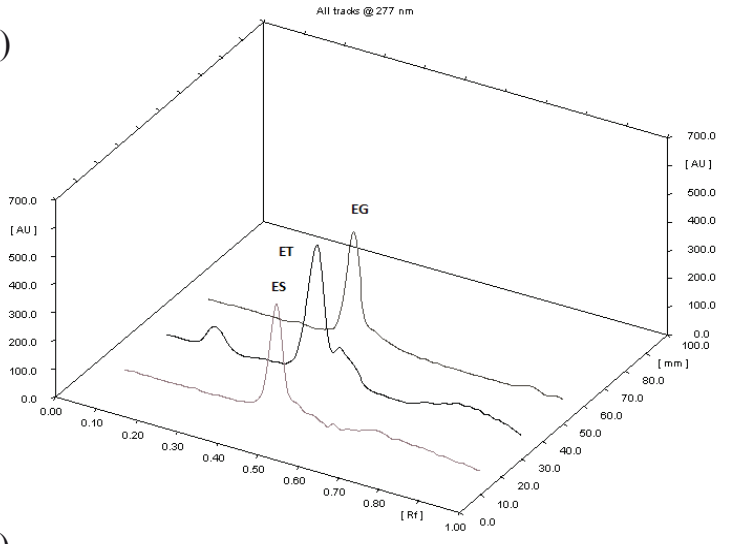

(B)

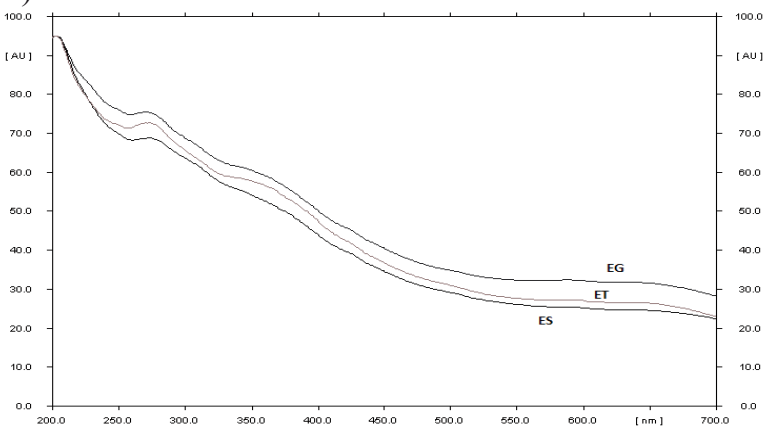

Figure 1. Exemplary densitogram (A) and spectrodensitogram (B) of a-escin coming from standard solution (ES), tablets (ET) and gel (EG), obtained by way of using n-butanol-acetic acidwater $(30: 7: 13, \mathrm{v} / \mathrm{v} / \mathrm{v})$ on chromatographic plates E. Merck Art. 1.05554 , and visualized through the application of $10 \%$ sulphuric acid in ethanol

(A)

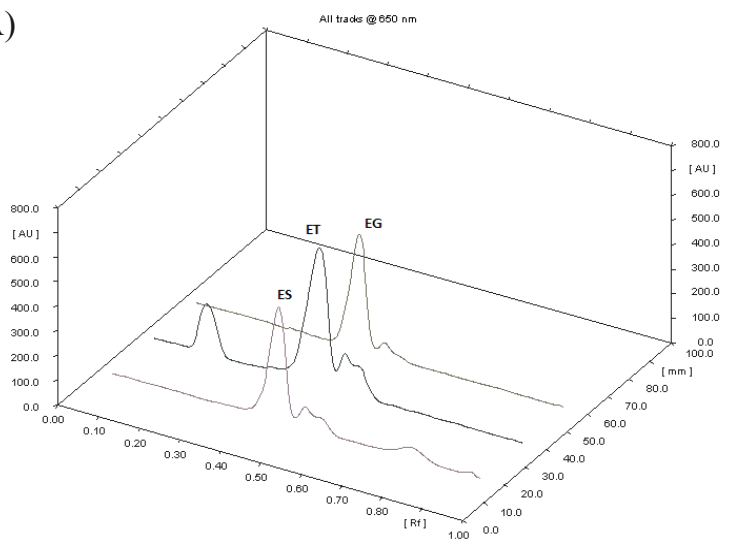

(B)

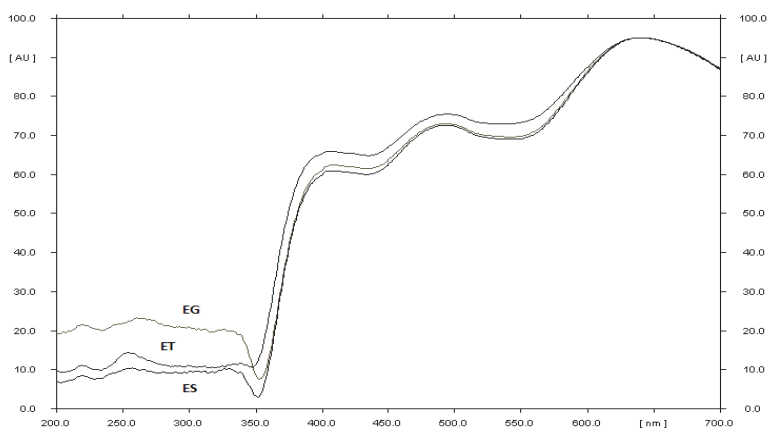

Figure 2. Exemplary densitogram (A) and spectrodensitogram (B) of $\alpha$-escin coming from standard solution (ES), tablets (ET) and gel (EG), obtained through using n-butanol-acetic acidwater $(30: 7: 13, \mathrm{v} / \mathrm{v} / \mathrm{v})$ on chromatographic plates E. Merck Art. 1.05554 , and visualized by way of the application of $5 \%$ vanillin in methanol/sulphuric acid.

\section{DISCUSSION}

The main goal of the presented work was to develop a simple and rapid TLC-densitometric method for determining $\alpha$-escin (Aescin) in bulk drug substances. The main problem within a TLC analysis combined with UV-VIS densitometry is the lack in the $\alpha$-escin structure of strong chromophore groups, a situation necessary for effective UV-VIS. Hence, we investigated the selection of appropriate chromatographic conditions, including suitable visualizing reagents, which could allow the obtaining of reliable and reproducible densitometric measurements from the examined compound.

In our study, chromatographic plates precoated with silica gel 60 , silica gel $60 \mathrm{~F}_{254}$ without and with a concentrating zone, and also a mixture of silica gel 60 and kieselguhr $\mathrm{F}_{254}$ were applied as stationary phases (E. Merck, Art. 1.05554, Art. 1.05553, Art. 1.05583, Art. 1.05567). Subsequently, different mobile phase systems consisting of various organic solvents accurately described in the experimental section, were tested. The TLC systems were then evaluated by determining the optimal retention factor $\left(\mathrm{R}_{\mathrm{F}}\right)$ of the examined compound. Additionally, in order to describe the efficacy of all applied chromatographic conditions for a TLC-densitometric study of $\alpha$-escin, the stability of the developed color of the substance's spots was assessed These have been visualized without dipping reagent and also by way of employing different dipping reagents: $10 \%$ sulphuric acid in ethanol, $5 \%$ vanillin in methanol/sulphuric acid, $10 \%$ phosphomolybdic acid in ethanol, $2 \%$ anisaldehyde in methanol/ sulphuric acid, $2 \%$ iodine/potassium iodide and $2 \%$ cobalt (II) chloride in methanol.

In our work, we saw that, generally, the use of methanolwater and acetone-water in varied volume compositions and applied chromatographic plates enabled the obtaining of $\mathrm{R}_{\mathrm{F}}$ near 0.99 . Similar results of retention factor could observed in the case of other mobile phases used in the preliminary investigations of $\alpha$-escin. Among these:

- acetonitrile-acetic acid water 30:7:13, v/v/v

- acetonitrile-isopropanol-acetic acid 15:15:7, v/v/v

- isopropanol-water-formic acid 35:12:3, v/v/v

- methanol-ethyl acetate-water 30:7:13, v/v/v.

What is more, the application of chloroform-methanol in volume composition 47:3 and acetone-n-hexane 8.5:41.5 $(\mathrm{v} / \mathrm{v})$ enabled the obtaining of an $\mathrm{R}_{\mathrm{F}}$ equal to 0 . In addition, the use of a mobile phase containing n-butanol, such as a mixture of n-butanol-acetic acid-water (BAW), which is generally recommended in literature $[6,13]$ for TLC-chromatographic separation of various triterpene compounds in plant material (e.g., plant extracts), significantly improved, in this work, the chromatographic behavior of the studied $\alpha$-escin as a bulk drug substance, as well as an active ingredient in two different dosage forms (tablets and gel).

The results of $\mathrm{R}_{\mathrm{F}}$ obtained for $\alpha$-escin spots using the above-mentioned solvent mixture, various chromatographic plates precoated with silica gel $60 / 60 \mathrm{~F}_{254}$ and its mixture with kieselguhr $\mathrm{F}_{254}$, as well as the visualization of the spots by means of all the applied dipping reagents and without the use of dipping reagent, are revealed in Table 1. The data seen in Table 1 confirm that, indeed, the mobile phase proposed in this work is the most suitable of all that had 
been applied in this experiment, because it allows the obtaining of best $\mathrm{R}_{\mathrm{F}}$ value for the investigated compound (placed in the range of 0.44-0.51). Moreover, the comparison of $\mathrm{R}_{\mathrm{F}}$ values and maximum wavelength $\left(\lambda_{\text {max }}\right)$ of the $\alpha$-escin spectra which has been examined on different chromatographic plates and visualized by way of the application of various types of dipping reagents, indicates that using the applied mobile phase n-butanol-acetic acid-water in a proportion of $30: 7: 13$, very similar $R_{F}$ values $(0.44 / 0.45)$ may be achieved by means of silica gel $60 \mathrm{~F}_{254}$ (Art. 1.05554) and silica gel 60 (Art. 1.05553).

The same conclusion could be formulated in the case of other applied chromatographic plates precoated with either silica gel $60 \mathrm{~F}_{254}$ with concentrating zone (Art. 1.05583), and that precoated with a mixture of silica gel 60 and kieselguhr $\mathrm{F}_{254}$ (Art. 1.05567). These allowed the obtaining of a similar value of $R_{F}$ for $\alpha$-escin $(0.50 / 0.51)$. This fact confirms that these chromatographic plates could be applied alternatively. Furthermore, an analysis of $\lambda_{\max }$ of the recorded UV-VIS spectra of the examined compound which has been studied under the described chromatographic conditions, and by way of using all the applied dipping reagents, demonstrates that the biggest similarity in behavior of $\alpha$-escin spots detected by the UV-VIS densitometric technique could be observed in the case of chromatographic bands obtained by $2 \%$ iodine/potassium iodide and $2 \%$ cobalt (II) chloride in methanol, and with those detected without dipping reagent $\left(\lambda_{\max }=221-224 \mathrm{~nm}\right)$. For chromatographic bands of $\alpha$-escin visualized by means of $10 \%$ sulphuric acid in ethanol and $2 \%$ anisaldehyde in methanol/sulphuric acid, the difference between $\lambda_{\max }$ is higher. It is of interest that the maximum absorption of the UV-VIS spectra of $\alpha$-escin visualized by way of application of 5\% vanillin in methanol/sulphuric acid, and 10\% phosphomolybdic acid in ethanol, are placed in the visible light wavelength range: $650-700 \mathrm{~nm}$ (Table 1).

In summarizing the results set out in Table 1, and on the basis of the observations of the stability of the spot color achieved by employing different types of visualizing reagents, we can state that the best TLC-densitometric analysis in combination with UV-VIS for $\alpha$-escin (having weak chromophores) is provided by applying $10 \%$ sulphuric acid in ethanol and also by applying 5\% vanillin in methanol/sulphuric acid as visualizing reagents. Both reagents are equally universal for the detection of $\alpha$-escin. Moreover, the color of spots and also $\lambda_{\text {max }}$ of the spectra are very stable during all densitometric analysis. Therefore, both visualizing reagents were applied in further TLC-densitometric studies of $\alpha$-escin.

In order to estimate the applicability of the developed method in the quantitative determination of $\alpha$-escin in bulk drug substances, the limit of detection (LOD) and also the limit of quantification (LOQ) of $\alpha$-escin by means of n-butanol-acetic acid-water in a volume composition 30:7:13 as mobile phase, the use of various chromatographic plates manufactured by E. Merck: Art. 1.05554, Art. 1.05553, Art. 1.05567 and Art. 1.05583 and the two above-mentioned visualizing reagents, were applied. The LOD and LOQ values obtained under these chromatographic conditions are presented in Table 2.
Based on the data listed in Table 2, we suggest that the TLC-densitometric method is not as sensitive as, for example, HPLC-MS/MS or other high-performance chromatographic techniques which allow for the determination of $\alpha$-escin content in biosamples in samples of nanogram size [8,14-15], but it is sensitive enough for determining $\alpha$-escin in pharmaceutical dosage forms containing $20 \mathrm{mg}$ of it or more. Our results indicate that the greatest sensitivity in TLC-densitometric determination of the examined compound by way of the described conditions could be achieved with the use of the two proposed dipping reagents, as well as employing chromatographic plates precoated with silica gel $60 \mathrm{~F}_{254}$ with concentrating zones (Art. 1.05583). In this case, LOD: 0.330-0.395 $\mu \mathrm{g} /$ spot and LOQ: 0.999-1.196 $\mu \mathrm{g} /$ spot were obtained (Table 2). The worst results (poorest sensitivity) are observed in the case of applied silica gel 60 plates analyzed without the use of both dipping reagents $(\mathrm{LOD}=11.390 \mu \mathrm{g} / \mathrm{spot}$ and $\mathrm{LOQ}=34.515 \mu \mathrm{g} / \mathrm{spot})$ - Art. 1.05553 .

A comparison of the LOD and LOQ values of $\alpha$-escin gained by way of utilizing the two applied visualizing reagents, with those developed without the dipping reagent, brings about a conclusion that the usage of the two proposed visualizing reagents: $5 \%$ vanillin in methanol/sulphuric acid and $10 \%$ sulphuric acid in ethanol, enables the obtaining of the best TLC-densitometric performance of $\alpha$-escin in bulk drug substance testing.

Figure 1 and Figure 2 are exemplary densitograms (Fig. $1 \mathrm{~A}$ and $1 \mathrm{~B}$ ) and spectrodensitograms (Fig. $2 \mathrm{~A}$ and $2 \mathrm{~B})$ of $\alpha$-escin that came about from assessing standard solution (ES), tablets (ET) and gel (EG). These have been investigated by way of employing silica gel $60 \mathrm{~F}_{254}$ plates (Art. 1.05554), n-butanol-acetic acid-water (30:7:13) and $10 \%$ sulphuric acid in ethanol (Fig. 1) or 5\% vanillin in methanol/sulphuric acid, respectively (Fig. 2). Such results demonstrate the utility of the developed TLC-densitometric method for successfully identifying $\alpha$-escin in bulk drug substances, as well as in two pharmaceutical dosage forms (tablets and gel). Thus, this method could be applied in the quality control of pharmaceuticals containing $\alpha$-escin in amounts of $20 \mathrm{mg}$ or more.

Careful analysis of the two densitograms of $\alpha$-escin generated by assessment of the tablet form (ET) (Figures $1 \mathrm{~A}$ and $2 \mathrm{~A}$ ), and the observation of the presence of an additional peak (revealing poor separation within the $\alpha$-escin sample) denotes that in order to obtain reliable quantitative analysis of the studied $\alpha$-escin in the examined tablet dosage form, appropriate purification of sample is required.

Further research study of $\alpha$-escin will be continued in terms of quantitative analysis of this substance in both the examined pharmaceutical formulations by means of the developed method, after previous full validation (including its precision and repeatability) is undertaken.

\section{CONCLUSIONS}

The results presented in this work indicate that the developed TLC-densitometric method, which utilized n-butanol-acetic acid-water in a volume composition of 30:7:13, silica gel $60 \mathrm{~F}_{254}$ plates with concentrating zone, 
and also two proposed visualizing reagents: $5 \%$ vanillin in methanol/sulphuric acid and 10\% sulphuric acid in ethanol, enabled the identification of $\alpha$-escin in bulk drug substances and also in two pharmaceutical dosage forms (tablets and gel). In this work, the application of the above-mentioned dipping reagents greatly improved LOD and LOQ, hence, the efficacy of TLC-densitometric measurements of $\alpha$-escin in the bulk drug substance sample. This experiment demonstrates the usefulness of a simple TLC-densitometric method in the qualitative control of $\alpha$-escin in two various commercial dosage forms. What is more, the developed method may be successfully applied in further quantitative determination of this substance in both investigated pharmaceutical formulations, as a good alternative to other, especially more expensive techniques. Further quantitative investigations of $\alpha$-escin as the active ingredient within two pharmaceutical formulations, tablets and gel, using the developed TLC-densitometric technique and including a purification step in the preparation of the obtained extracts, will be continued. A full validation procedure of the proposed TLC method in terms of other parameters such as its precision and repeatability, will be done in the near future.

\section{ACKNOWLEDGEMENT}

This work was financed by Medical University of Silesia in Katowice as part of statutory research project in 2014 year, project No. KNW-1-006/N/4/0.

\section{REFERENCES}

1. Acar, A. M., Paksoy, S.: Derivative spectrophotometric determination of escin in Aesculus hippocastanum L. seeds. Pharmazie, 48, 65-66, 1993.

2. Apers, S., et al.: Densitometric thin-layer chromatography chromatographic determination of aescin in a herbal medicinal products containing Aesculus and Vitis dry extracts. J. Chromatogr., A. 1112, 165-170, 2006.
3. Connolly, J. D, Hill, R. A.: Triterpenoids. Nat Prod Rep., 27(1), 79-132, 2010.

4. Costantini, A.: Escin in pharmaceutical oral dosage forms: quantitative densitometric HPTLC determination. II Farmaco, 54, 728-732, 2013.

5. European Pharmacopoeia, 6th Ed. 20(3), 478-481, European Pharmacopoeia Commission, UK, London, 2008.

6. Gołembiewska, E., et al.: Methods for the isolation and identification of triterpenes and sterols in medicinal plants. Curr. Issues Pharm. Med. Sci., 26(1), 26-32, 2013.

7. Lindner, I., et al.: Beta-escin has potent anti-allergic efficacy and reduces allergic airway inflammation. BMC Immunol., 21, 11-24, 2010.

8. Liu, L., et al.: A liquid chromatography-tandem mass spectrometry method for the simultaneous quantification of escin Ia and escin Ib in human plasma: application to a pharmacokinetic study after intravenous administration. Biomed. Chromatogr., 24, 1309-1315, 2010.

9. Man, S.: Chemical study and medical application of saponins as anti-cancer agents. Fitoterapia ${ }_{2}$ 81(7), 703-714, 2010.

10. Rao, A. V, Gurfinkel, D. M.: The bioactivity of saponins: triterpenoid and steroidal glycosides. Drug Metabol Drug Interact., 17(1-4), 211-235, 2000.

11. Sirtori, C. S.: Aescin: pharmacology, pharmacokinetics and therapeutic profile. Pharmacol. Res., 44 (3), 183-193, 2001.

12. Vujic, Z.: Optimization of the extraction process of escin from dried seeds of Aesculus hippocastanum L. by Derringer's desirability function. J. Anim. Plant Sci., 17(1), 2514 -2521, 2013.

13. Waksumundzka-Hajnos, M., et al.: Thin Layer Chromatography in Phytochemistry. TLC of Triterpenes (Including Saponins). 20, 519-537, CRC Press, Boca Raton, 2008.

14. $\mathrm{Wu}, \mathrm{X}$. J., et al.: Comparative pharmacokinetics and the bioavailability of escin Ib and isoescin Ib following the administration of escin, pure escin Ib and isoescin Ib in rat. J Ethnopharm. 139, 201-206, 2012.

15. Zhang, M., et al.: Simultaneous Determination of escin Ia and Its isomer isoescin Ia by LC-MS-MS: Application to a pharmacokinetic study of escin Ia in rats. Chromatographia. 74 (3-4), 243-250, 2011.

16. Zhou X. Y., et. al.: Escin, a natural mixture of triterpene saponins, exhibits antitumor activity against hepatocellular carcinoma. Planta Med. 75(15), 1580-1585, 2009. 